\title{
The need to redesign the hospital ICUs for COVID-19 patients to save the medical fraternity
}

\author{
Ramakrishnan, Angarai Ganesan and Kanishka Sharma \\ agr@iisc.ac.in, kanishkas@iisc.ac.in \\ MILE Laboratory, Department of Electrical Engineering, \\ Indian Institute of Science, Bangalore 560012, INDIA.
}

\begin{abstract}
It is of utmost importance to protect our health-care professionals, who are the most important resources for any country today. The commitment behind this article and proposal is to ensure that we do not lose even one more doctor or nurse to COVID-19. In the opinion of the authors, the current design of most of the ICUs, where the air is recirculated through the air-conditioning, is not suited for treating the highly infectious patients of COVID-19, and may be one of the causes of the thousands of infections among the healthcare workers, which has also led to the death of over 500 of them around the world. One is not sure whether this is the reason behind the unusual death rate of patients put on ventilators too. This article proposes a cost-effective redesign of the existing ICUs and suggestions for choosing the buildings intended to be converted to makeshift hospitals to take care of the patients infected by the corona virus. Also, where the personal protective equipment is in shortage, certain possible alternatives are suggested.
\end{abstract}

Keywords: SARS-CoV, SARS-CoV-2, COVID-19, Intensive care units (ICU), air-conditioning, personal protective equipment, infectious medical waste, disposal, disinfection

\section{Background and current status}

In 2003, the SARS outbreak in Hong Kong became a global threat affecting 30 countries [1]. At that time too, people at the greatest risk were health workers exposed to the patients or by procedures such as intubation, aerosolized medication and laboratory people handling human secretions [2]. A study on healthcare workers exposed to SARS-CoV patients made a shocking revelation that $56 \%(n=80)$ of them were found to be asymptomatically infected even while using N95 masks, gloves and gowns [3]. Further, in the case of SARS-CoV in Hong Kong, the frontline health workers were found with psychological stress and formed as much as thirty percent of the total infected population [4]. Thus, we need to have a close look at the conditions in the intensive care units meant for such highly infectious diseases.

The present situation is worse than that of the 2003 SARS CoV disease. Around the world, more than five hundred doctors, nurses and other health care professionals have died of COVID-19 infection, while serving patients at the ICUs [5]. While there are definitely other reasons such as lack of protective equipment, exhaustion, etc., we seriously think that the 
way the ICUs are designed today, may act against the health of the health workers themselves. We strongly feel that by immediately redesigning the ICUs, we can save or minimize the health workers from getting infected. While the normal death rate of patients put on ventilators is high, with COVID-19 patients, it is reported to be much higher [6,7]. In fact, since nearly $50 \%$ of the patients do not exactly match the criteria for acute respiratory distress syndrome, there is naturally a difference of opinion among the doctors on the use and the time of application of the only treatment strategy, namely, the ventilator [8]. Mortality rate is eventually higher in ICU patients aged more than 60 years, who have comorbid conditions such as hypertension $[9,10]$.

The guidelines of the Indian Society of Critical Care Medicine recommend that the ICUs serving the critically ill patients have a filtering efficiency of $99 \%$ for particles above the size of 5 micron [6]. Negative air pressure is suggested as a necessity in these units dealing with infectious disease spread through airborne droplets with microbes of size less than 5 micron $[11,12]$. Even with these guidelines, the filter efficiency dealing with the smaller size of SARS CoV-2 is questionable. Almost all the ICUs are airconditioned and the same air is recirculated through the air-conditioner and it does not effectively get filtered for viruses of smaller size. Of course, some companies do have products with filters of those capabilities, but most hospitals do not have these models installed today.

From the Japanese simulation study [13] on how the virus spreads in a closed room, and how it quickly disperses in a room with windows, it is very clear that the ICUs as they exist today are a matter of concern not only for the patients, but also for the doctors and nurses. A recent study at MIT showed that arbitrary droplet size cut-offs and the social distancing of a minimum of one meter may not provide efficient protection from respiration emission for SARS-CoV2.[10]. With fast track experimental research on COVID-19, the recommended safety measures as well as the critical information about the infection spread are rapidly changing $[15,16]$.

In the considered opinion of the authors, the recirculation of the air by the centralized air-conditioning systems is what has led to the significant infection of our committed medical fraternity and has also led to deaths of doctors and nurses. It is also our considered opinion that none of the masks will be fully protective, if the air around is fully infected by the diffusion of the air constantly being breathed out by the patients, when a large number of patients are being taken care of in a (makeshift) ICU.

We suggest the following possible solutions, depending upon the density of patients being attended to, availability of personal protective equipment (PPE), availability of sufficient number of health workers, whether it is a regular or a make-shift hospital, funds, etc.

(i) Cost-effective solutions for some countries, say in Africa, lacking ICU, etc.

Instead of converting buildings into makeshift hospitals, the authors feel it is preferable to convert big, open grounds for monitoring infected patients, who have no complications and are only under observation, probably with oxygen saturation being monitored. 
(ii) If air-conditioning is NOT a must: Create a forceful, unidirectional flow of air in the ICU. Let the exhaust air bubble through a disinfecting soap or sodium hypocholorite solution or very hot water.

Studies clearly show that higher the temperature, faster the corona virus becomes inactive [17]. Thus, the authors suggest that airconditioning can be dispensed with. In this case, the fundamental change we are suggesting for ICUs taking care of COVID-19 and any other such contagious patients is that there must be a swift draft of air through the ICU in a single direction. On the entry side of the air, there must be active pushing in of the air with powerful (industrial type, with low noise) fans. On the exit site of the air, there must be powerful exhaust fans pulling the air out, and we must design in such a way that this air passes through a tube and bubbles through multiple chambers of a solution of soap or (simple soap in simple water) or sodium hypochlorite to assure that any virus in the air gets disintegrated or disinfected by the time the air finally comes out of the multiple bubbling chambers. Soap is the best way of eliminating the virus from the infected air [18]. Soap and surfactants have a property to form micelles and to wedge themselves into the protein, lipid bilayer in the case of infectious bacteria and virus. The soap action on H1N1 [19], inflenza [20] and Ebola [21] has been found to be very effective and established as one of the best ways of disinfection, with consistent results. However, the soap solution has the problem of frothing, which needs to be suitably managed. Chemical engineers need to give an appropriate solution to this, if possible. It may be possible to direct the air stream alternately through two sets of soap solution chambers and eliminate the froth in the inactive chambers suitably, when the air is made to pass through the other set of chambers.

Alcohol is preferably not used in this application, since we need large quantities of the same, where it is highly inflammable. Sodium hypochlorite solution of a suitable dilution can be used, but needs to be refreshed every day [22]. However, at high concentration, it is corrosive and can cause nasal and skin irritation, sore throat and coughing and hence, the personnel handling it needs proper training and protection equipment. Indian society of heating, refrigerating and air conditioning engineers (ISHRAE) suggests the use of high efficiency particulate air (HEPA) filters, but unless they are certified for this (at least H13 (EN1822-1) filter class) [23], HEPA filters will NOT be able to filter out the SARS CoV2 virus, which is 0.08 to 0.16 micrometer in size [24]. Further, HEPA filters only filter the virus based on its size, leaving the live virus on the filter, to be disinfected periodically later. Thus, they are again not advisable. On the other hand, sodium hypochlorite [22] or soap chemically annihilate the virus [18] by destroying their structural integrity and thus are preferable. The disinfected air can again be sent through one or two chambers of water to remove the soap or chemical molecules in the air. This clean air can again be circulated OR left into the atmosphere, depending upon what works. Clearly, these solutions require the design and expertise of fluid mechanics engineers.

The third alternative is to pass the exhaust (virus-laden) air through very hot water, being continuously heated by coils, similar to a geyser. It has been reported that at a temperature of $70^{\circ} \mathrm{C}$, the virus gets inactivated within 5 minutes [17]. Hence, it is likely to get inactivated even faster with the use of near-boiling water. In this case, it is preferable to let the 
disinfected air into the atmosphere, since it is hot. Figure 1 gives a tentative schematic diagram, illustrating the method suggested for disinfecting the exhaust air from ICU.

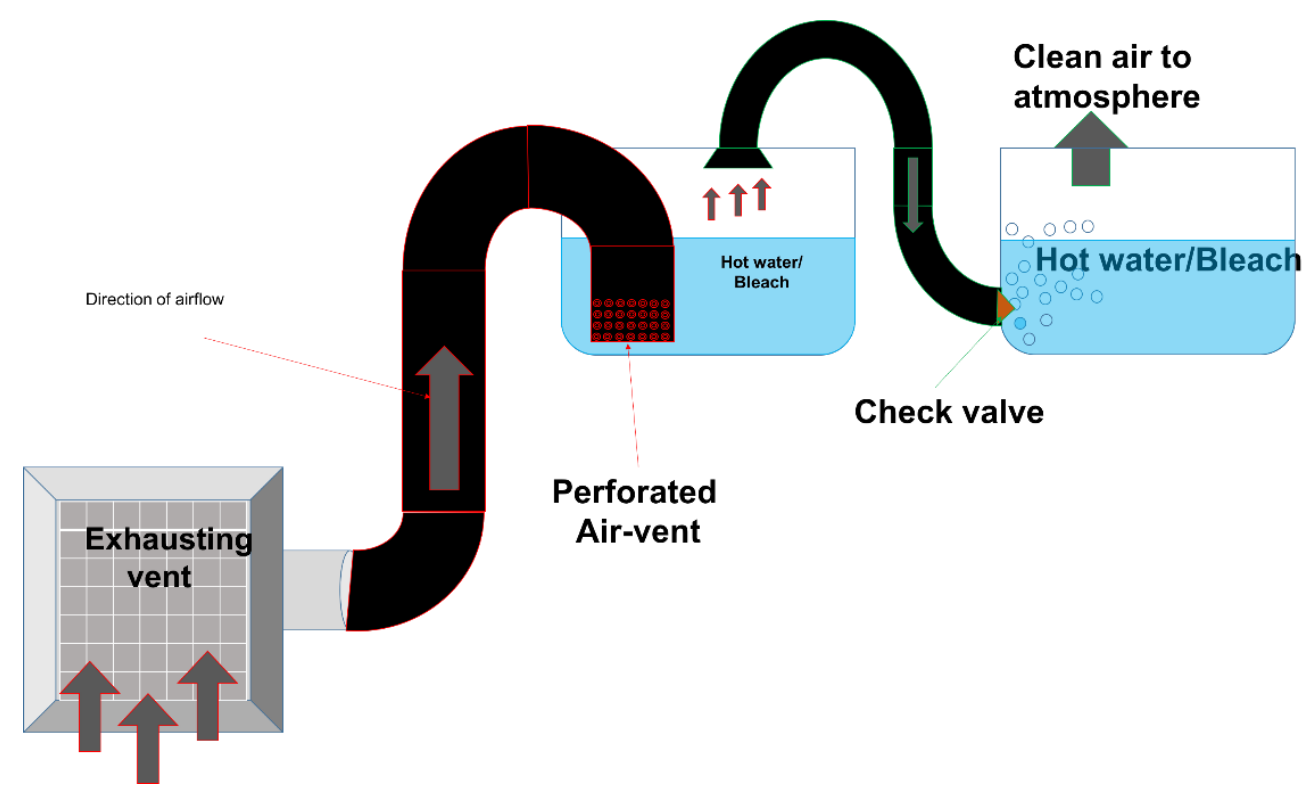

Fig. 1. A conceptual diagram illustrating the possible disinfection of ICU exhaust air, by a sequence of chambers containing a disinfecting solution or near-boiling water.

(iii) If air-conditioning is a must: No forceful flow; Let the exhaust air go through an appropriate disinfecting solution.

In this case, it is really important to ensure that the air-conditioning of the COVID-ICU is delinked from that of the other (non-COVID-19) ICUs in the hospital to avoid the air that comes out of the COVID-19 ICU from being recirculated to the other ICUs. We do not need the fans that forcefully send air into the ICU. The exhaust fans and the filtering by making the air pass through multiple chambers of disinfecting solution remain, as in the case (ii) above.

(iv) If a new area is converted into a makeshift COVID-19 ICU or if there are closed windows in the current ICU: Open all the closed windows of the current ICU or choose the new place with as many windows as possible, so that the aerosols (and hence the virus) disperses as fast as possible.

The latest review published after the current pandemic outbreak has recommended to have a single room with proper ventilation for each critically ill patient, if no negative pressure infrastructure is available [12]. However, this may be impractical and expensive, if we need to modify an existing ICU facility. However, in case the hospital ICU has a number of windows that have been closed for increasing the efficiency of $A / C$ cooling, all the windows may be opened and the air-conditioning switched off. If a makeshift hospital or ICU is planned, then one must choose a hall or a building, which has a lot of windows and ventilation, and if needed, both blow-in and exhaust fans may be used to create a constantly moving, unidirectional flow of air. 
Circulation of air exhaled by infected patients in the ICU or COVID-19 units may contribute to fast transmission of infection as well as severity of already infected patients. Elias and Bar-Yam [25] suggest separate filtration of air exhaled from each patient's lungs in order to reduce the amount of virions present in the lung and the upper respiratory tract as well as the immune hyper response associated with cytokine storm. A wearable filter for patients or patient cohort may be an effective measure to reduce the viral load in the air as well as the patient's body [25].

The Indian Railways has converted several railway coaches into temporary ICUs for the care of COVID-19 patients [26], in case required. In this makeshift arrangement, it is ideal to use the conventional non-AC coaches with all the windows open.

\section{Requirements in toilets}

It is more than clear that the chances of infection are very high in the toilets. Hence, all the water taps in all the toilets must be of the contactless variety, so that neither the doctors, nor the nurses nor patients need to touch any of the taps to open or close them. This shall minimize the viral load on the taps and also the frequency of disinfection needed. Further, when the patient is able enough to visit the toilet himself/herself, it is not advisable to use toilet paper, since it does not lead to any disinfection at all. It is better to provide a warm water jet, with a small amount of soap in it, which can neutralize the virus. Similarly, the flush water may also be loaded with the minimum required concentration of bleach to disintegrate the virus present in the excreta then and there.

In case the patient is not in a condition to visit the toilet and is being nursed, appropriately modified procedures may be adopted to ensure disinfection of the patient's body and the refuse, as much as possible.

We discuss other connected issues below.

\section{Keep elderly doctors away from direct patient care}

Many senior doctors have also sacrificed their lives in the service of Covid-19 patients [5]. This could have been avoided. Aged and senior physicians must preferably be used as advisors to young doctors, and current postgraduate students in medical institutions, belonging to every specialty should be utilized by the Governments of every country to serve the COVID-19 patients as part of their training programme. While providing a sufficient number of young skilled professionals, this will also ensure less casualties among the medical fraternity, by keeping the more vulnerable elderly physicians away from directly dealing with the infected patients.

\section{Reusable, affordable personal protective gowns}

The authors are making the following suggestions for poor countries, which could ill-afford single use personal protective gowns or do not have sufficient supplies of them. Ultimately, if this idea works out, it shall lead to a huge environmental benefit to the world, by minimizing the use of all possible single-use materials in hospitals, and hence, the need for expensive disposal mechanisms and technologies for their careful disposal. In many cases, even 
Governmental regulations and policing are required to ensure the safe disposal of contaminated hospital wastes, and the suggested measures may reduce the strain on even the administration.

Improper removal and disposal of contaminated, disposable personal protective gowns can expose other people to infectious agents. In this context, it is unfortunate that in some hospitals of even advanced countries, the medical personnel have been asked to use the same mask for three consecutive days, because of inadequate supplies. Since it is clear that the Covid-19 virus does not enter through the intact skin, the hospitals or the health authorities in poor countries can supply easily washable, regular clothes to the HCW, along with the protective mask for the face alone. Once the duty is over, the HCW must directly enter a bathroom, have a shower and leave all his/her clothes in the washing machine. Washing the clothes with soap not only effectively destroys the virus and disinfects the clothes, but also it solves the huge medical waste disposal problem.

\section{Use machine-washable shoes for the HCW and disinfecting doormats}

There is recent evidence from the Centres for Disease Control and Prevention (CDC) that corona virus can spread through shoes. Once again, we must use easily machine-washable shoes with appropriate materials (if needed, manufacture them in sufficient numbers) so that the HCW dumps the shoes also into the washing machine and goes out with his/her own shoes. Further, the doormat outside the ICU must have a disinfectant, so that the nurses and other health workers disinfect the bottom of their shoes, before walking into the other areas of the hospital. Once again, a simple sponge dipped in soap water, kept in a broad, shallow tub must do the job. There must be another sponge dipped in normal water, to remove the slippery soap from the bottom of the shoes. Once again, we do not recommend the use of corrosive sodium hypochlorite; however, even that is better than not having anything to disinfect the shoes. These are some affordable, simple but very effective measures.

\section{Separate resting chambers for the doctors and nurses post working hours}

Our medical fraternity goes through extreme stress, exhaustion, etc. So, we need to create a small space, wherein the doctors can go in and refresh and recharge themselves quickly. We can provide (i) availability of hot, tasty soups with turmeric and black pepper added [27], (ii) a water fountain or water flowing down one of the walls, creating negative ions in the air, effective against occupational stress and anxiety [28], (iii) show videos of simple pranayama and yogasanas, which refresh them and increases their immunity [29], (iv) (i) soothing music [31]: preferably, choosable by the health worker based ion his/her taste, etc. and so on. Manifold benefits of music listening [30] and music making [31] have been observed on healthcare workers in the form of burnout symptoms, stress reduction as well as surgical efficiency. If possible, the walls may have wallpaper, depicting lush, green, nature.

\section{Rotate the doctors and nurses every few hours}

Many physicians, including specialists in other areas, are relatively free these days, since most people are avoiding going to hospitals (except for emergencies) for fear of 
infection or due to lock-down. Similarly, independent practitioners and nurses from private hospitals may be free of work. Hospitals can get financial support from the State or Central government and recruit any of the above doctors and nurses, who are ready to come and help (temporarily, till we win over the novel Corona virus). Since there are no specific medicines and the patients have no other wound born of surgery, etc., any other willing doctor or nurse can be trained to handle these patients in a finite time by someone with experience. Also, in every country, senior, final year medical students can be mandated by the respective Governments to assist in these special COVID-19 intensive care units. This will immediately provide sufficient supply of trained manpower in hospitals; the students can be given some credit in terms of merit points, which can be appropriately recognized later.

This way, there will be adequate availability of doctors, nurses and any other type of support workers. They can be rotated after every 6 or 8 hours, depending upon what works.

\section{Soothing music for the patients too}

The patients are also under extreme stress, normally in any ICU [32], and more so in the COVID-19 case. So, we must think of whatever we could do, to reduce their stress and keep them at relative ease, and one of the things we can think of immediately, is music.

\section{Conclusion}

The current outbreak has once again made us realize the importance of healthcare workers as the most valuable resource [33] and it is of utmost priority to provide them effective PPEs as well as a safe and disinfected environment and ensure their security. We appeal to engineering design researchers to work on an innovative and effective design for a soap-based air filter in order to treat the infected air in ICU and COVID-19 wards. Strong and prompt measures are needed to be taken at the policy level to implement these designs quickly to stem the infection of healthcare workers.

Finally, a word of caution. The world has been suddenly and unexpectedly attacked by this virus and everything about how to handle the situation, patients, economy, etc. are being actively discussed and changes are being made every day. Similarly, this article has been written with currently available knowledge and a sincere intention to help the medical community handle the patients with best possible caution, with the given facilities and constraints. Hence, some of the suggestions made here are also subject to change with time, in a dynamic manner, with additional knowledge and practical considerations coming in.

\section{References}

1. Zhong, N. S., Zheng, B. J., Li, Y. M., Poon, L. L. M., Xie, Z. H., Chan, K. H., Li, P.H., Tan, S.Y., Chang, Q., Xie, J.P. and Liu, X. Q. (2003). Epidemiology and cause of severe acute respiratory syndrome (SARS) in Guangdong, People's Republic of China, February, 2003. The Lancet, 362(9393), 1353-1358.

2. Oberholtzer, K., Sivitz, L., Mack, A., Lemon, S., Mahmoud, A., \& Knobler, S. (Eds.). (2004). Learning from SARS: Preparing for the Next Disease Outbreak: Workshop Summary. National Academies Press. 
3. Wilder-Smith, A., Teleman, M. D., Heng, B. H., Earnest, A., Ling, A. E., \& Leo, Y. S. (2005). Asymptomatic SARS coronavirus infection among healthcare workers, Singapore. Emerging infectious diseases, 11(7), 1142-1145. https://doi.org/10.3201/eid1107.041165

4. Tam, C. W., Pang, E. P., Lam, L. C., \& Chiu, H. F. (2004). Severe acute respiratory syndrome (SARS) in Hong Kong in 2003: stress and psychological impact among frontline healthcare workers. Psychological medicine, 34(7), 1197-1204.

5. In Memoriam: Healthcare Workers Who Have Died of COVID-19, https://www.medscape.com/viewarticle/927976, last accessed April 14, 2020.

6. Some doctors moving away from ventilators for virus patients, https://apnews.com/8ccd325c2be9bf454c2128dcb7bd616d, last accessed April 14, 2020. 3.

7. Ñamendys-Silva, S. A. (2020). Respiratory support for patients with COVID-19 infection. The Lancet Respiratory Medicine, 8(4), e18.

8. Luciano Gattinoni, Silvia Coppola, Massimo Cressoni, Mattia Busana, Sandra Rossi, Davide Chiumell. (2020). Covid-19 does not lead to a "typical" acute respiratory distress syndrome. Letter, American Journal of Respiratory and Critical Care Medicine, published March 30.

9. Zhou, F., Yu, T., Du, R., Fan, G., Liu, Y., Liu, Z., Xiang, J., Wang, Y., Song, B., Gu, X. and Guan, L. (2020). Clinical course and risk factors for mortality of adult inpatients with COVID-19 in Wuhan, China: a retrospective cohort study. The Lancet.

10. Grasselli, G., Zangrillo, A., Zanella, A., Antonelli, M., Cabrini, L., Castelli, A., Cereda, D., Coluccello, A., Foti, G., Fumagalli, R. and lotti, G. (2020). Baseline characteristics and outcomes of 1591 patients infected with SARS-CoV-2 admitted to ICUs of the Lombardy region, Italy. JAMA.

11. Rungta, N., Govil, D., \& Nainan, S. (2010). ICU planning and designing in Indiaguidelines 2010. ISCCM Guidelines Committee.

12. Phua, J., Weng, L., Ling, L., Egi, M., Lim, C. M., Divatia, J. V., Shrestha, B.R., Arabi, Y.M., Ng, J., Gomersall, C.D. and Nishimura, M. (2020). Intensive care management of coronavirus disease 2019 (COVID-19): challenges and recommendations. The Lancet Respiratory Medicine.

13. Japanese explanation how sneeze https://www.youtube.com/watch?v=MOFdomaylxw, last accessed April 14, 2020.

14. Ong, S. W. X., Tan, Y. K., Chia, P. Y., Lee, T. H., Ng, O. T., Wong, M. S. Y., and Marimuthu, K. (2020). Air, surface environmental, and personal protective equipment contamination by severe acute respiratory syndrome coronavirus 2 (SARS-CoV-2) from a symptomatic patient. Jama.

15. Tang, J. W., Nicolle, A. D., Klettner, C. A., Pantelic, J., Wang, L., Suhaimi, A. B., Tan, A.Y., Ong, G.W., Su, R., Sekhar, C. and Cheong, D. D. (2013). Airflow dynamics of human jets: sneezing and breathing-potential sources of infectious aerosols. PLoS One, 8(4).

16. van Doremalen, N., Bushmaker, T., Morris, D. H., Holbrook, M. G., Gamble, A., Williamson, B. N., Tamin, A., Harcourt, J.L., Thornburg, N.J., Gerber, S.I. and Lloyd-Smith, J. O. (2020). Aerosol and surface stability of SARS-CoV-2 as compared with SARS-CoV1. New England Journal of Medicine.

17. Chin, A., Chu, J., Perera, M., Hui, K., Yen, H. L., Chan, M., Peiris, M. and Poon, L. (2020). Stability of SARS-CoV-2 in different environmental conditions. medRxiv. 
18. Fighting coronavirus with soap, https://www.youtube.com/watch?v=s2EVlqql_f8 . last accessed April 15, 2020.

19. Grayson, M. L., Melvani, S., Druce, J., Barr, I. G., Ballard, S. A., Johnson, P. D., Mastorakos, T. and Birch, C. (2009). Efficacy of soap and water and alcohol-based handrub preparations against live H1N1 influenza virus on the hands of human volunteers. Clinical Infectious Diseases, 48(3), 285-291.

20. Stock, C. C., \& Francis Jr, T. (1940). The inactivation of the virus of epidemic influenza by soaps. The Journal of experimental medicine, 71(5), 661.

21. Wolfe, M. K., Gallandat, K., \& Lantagne, D. (2017). Handwashing and Ebola virus disease outbreaks: A randomized comparison of soap, hand sanitizer, and $0.05 \%$ chlorine solutions on the inactivation and removal of model organisms Phi6 and E. coli from hands and persistence in rinse water. PloS one, 12(2).

22. World Health Organization, "Collecting, preserving and shipping specimens for the diagnosis of avian influenza $A(H 5 N 1)$ virus infection: guide for field operations," Geneva: World Health Organization, 2006.

23. ISO 29463 - New test standard for HEPA Filters, https://www.emw.de/en/filtercampus/iso29463.html, last accessed April 14, 2020.

24. Sahin, A. R., Erdogan, A., Agaoglu, P. M., Dineri, Y., Cakirci, A. Y., Senel, M. E., Okyay, R. A. and Tasdogan, A. M. (2020). 2019 Novel Coronavirus (COVID-19) outbreak: a review of the current literature. EJMO, 4(1), 1-7.

25. Elias, B., \& Bar-Yam, Y. (2020). Could air filtration reduce COVID-19 severity and spread?

26. Indian Railways to deploy more than 2500 doctors and 35000 paramedic staff to meet the COVID 19 challenge. (n.d.). Retrieved from https://pib.gov.in/PressReleaselframePage.aspx?PRID $=1612283$

27. Shoba, Guido, David Joy, Thangam Joseph, Mudassir Majeed, Ramaswamy Rajendran, and P. S. S. R. Srinivas. "Influence of piperine on the pharmacokinetics of curcumin in animals and human volunteers." Planta medica 64, no. 04 (1998): 353-356.

28. Nakane, H., Asami, O., Yamada, Y., \& Ohira, H. (2002). Effect of negative air ions on computer operation, anxiety and salivary chromogranin A-like immunoreactivity. International Journal of Psychophysiology, 46(1), 85-89.

29. Qu, Su, Solveig Mjelstad Olafsrud, Leonardo A. Meza-Zepeda, and Fahri Saatcioglu. "Rapid gene expression changes in peripheral blood lymphocytes upon practice of a comprehensive yoga program." PloS one 8, no. 4 (2013): e61910.

30. Ruotsalainen, J., Serra, C., Marine, A., \& Verbeek, J. (2008). Systematic review of interventions for reducing occupational stress in health care workers. Scandinavian journal of work, environment \& health, 169-178.

31. Loewy, J. V., \& Hara, A. F. (2002). Caring for the Caregiver: The use of music and music therapy in grief and trauma. American Music Therapy Association. 8455 Colesville Road Suite 1000, Silver Spring, MD 20910. 2.

32. McCowen, Karen C., Atul Malhotra, and Bruce R. Bistrian. "Stress-induced hyperglycemia." Critical care clinics 17, no. 1 (2001): 107-124.

33. Lancet, T. (2020). COVID-19: Protecting health-care workers. Lancet (London, England), 395(10228), 922. 